\title{
Biological prospecting: the ethics of exclusive reward from Antarctic activity
}

\author{
Julia Jabour* \\ Institute of Antarctic \& Southern Ocean Studies, University of Tasmania, Private Bag 77, Hobart, Tasmania 7001, Australia
}

\begin{abstract}
Biological prospecting is being undertaken in the Antarctic and, as novel material starts to yield significantly higher commercial rewards, the Antarctic Treaty Consultative Parties might decide to regulate it through the Antarctic Treaty System. This will be problematic since activities are already being undertaken, patents have been filed and products developed. Furthermore, there are differing perceptions of the status of the Antarctic, with some considering it global commons and others considering it the common heritage of mankind. These 2 doctrines can be inferred from the rhetoric of the Treaty and its subsequent legal instruments through which human activities, including the use of resources, are managed. However, the Antarctic Treaty System does not support either in practice because activities such as fishing and bioprospecting already return an exclusive reward for effort, with no benefit-sharing arrangements. Under the Convention on the Conservation of Antarctic Marine Living Resources, the Parties determine allowable catches for a fishery based on scientific assessment, and this may discharge them from providing access and benefit-sharing arrangements to the international community potentially available through other international law (e.g. the Law of the Sea Convention or the Convention on Biological Diversity). The major turning point in Antarctica came when the Convention on the Regulation of Antarctic Mineral Resource Activities - which acknowledged the rights of the international community - failed to enter into force. Today the international community is rewarded with a relatively healthy Antarctic environment and free access to some scientific information, which are benefiting all mankind. But the international community does not get direct financial reward from Antarctic activities because access is constrained by law and by a lack of capacity. There is no mechanism for disbursing compensation to all mankind in any case, although the Antarctic Treaty Consultative Parties could certainly rectify this if they had the will to do so. So far they have not.
\end{abstract}

KEY WORDS: Antarctica - Southern Ocean · Bioprospecting · Biological prospecting · Global commons $\cdot$ Common heritage $\cdot \mathrm{CCAMLR} \cdot \mathrm{CRAMRA}$

\section{BACKGROUND}

Activities such as collecting samples of biological material (bioprospecting) in the Antarctic (i.e. the continent of Antarctica and the Southern Ocean surrounding it) are being undertaken on an increasing scale and for a range of potential applications (Foster et al. 2009, UNU-IAS 2009). The Antarctic is a perfect target for a number of reasons: (1) It is subject to an extreme climate, meaning that its fauna and flora, which have been relatively undisturbed and isolated for millennia, have made novel functional adaptations to enhance their continued survival. (2) Scientific knowledge about Antarctic organisms is still comparatively naïve; consequently there is potentially a greater chance of novelty being present, especially in marine organisms. For example, it is now known that krill oil is high in polyunsaturated omega-3 fatty acids that have nutraceutical applications, and the antifreeze polypeptides or glycopeptides found in some fish species have important uses in medical technology (UNU-IAS 2009). 
To scientists and investors, the Antarctic presents an exciting resource. However, bioprospecting as it is currently being undertaken is raising interesting issues the answers to which are not, so far at least, wholly satisfactory from an egalitarian point of view. For example, it was reported recently that Antarctic bioprospecting has neither accepted definitions, nor clarity about jurisdictional scope, regulatory status, access arrangements, environmental implications, commercial use of material and information or benefit-sharing (Netherlands Government 2008). In common with many areas of the world, Antarctic bioprospecting is already happening, patents are being filed and products developed inside this management vacuum.

Scientists from different countries, including many from Antarctic Treaty Consultative Parties (ATCPs), ${ }^{1}$ are undertaking bioprospecting activities there (e.g. collecting samples of soil, water and organisms) as part of government-funded scientific research. However the ATCPs as the decision-making group have been reluctant to extend regulation over these activities beyond what is already required for any authorised activity in the Antarctic (e.g. scientific research, operational support or tourism). The subject of bioprospecting has been on Antarctic Treaty Consultative Meeting (ATCM) agendas since around 2002 (Jabour-Green \& Nicol 2003) and in 2009 the Parties decided that bioprospecting was adequately regulated for the time being by existing laws (ATCP 2009). What may be seen as a management vacuum globally is not, in fact, considered to exist within the Antarctic legal regime.

Since 2002 a group of Australian researchers has been following applications for patents in the US and European Patent Databases that relate to krill-derived material (Foster et al. 2009) and their results show a significant increase in the number of patents being filed. In addition, a recent joint United Nations University/United Nations Environment Program initiativethe 'Bioprospector' database - has been established (UNU-IAS 2009). It contains useful information on Antarctic bioprospecting activities although the data can only give a rough indication of the scale because of intellectual property confidentiality. It is in this context of actual, rather than hypothetical, activity that aspects of bioprospecting - including those related to the ethics of pursuing economic activities in the Antarctic for exclusive gain - are examined here.

\footnotetext{
${ }^{1}$ States that were either original signatories in 1959, or have acceded to the Antarctic Treaty since and can demonstrate substantial scientific research activity, may become Consultative Parties. All other states either succeeding or acceding to the Treaty attend meetings but do not take part in decision-making. The term ATCP will be used throughout this paper as it is this group that will make decisions about bioprospecting
}

The unique physical attributes of the Antarctic, including the temperature, light and ice regimes, attract the attention of bioprospectors looking for novelty. However, the place is also unique from the perspective of its political and legal status, which is sui generis. This is because unproven claims to sovereignty over parts of Antarctica have generated a multilateral treaty regime, implemented domestically, which is dedicated to managing all human use of the Antarctic and its resources. This paper explores whether Antarctica's uniqueness excuses the ATCPs from access and benefit-sharing obligations that they might otherwise owe to the international community from an unowned area, for example the Southern Ocean seabed. If such an excuse is invoked, what does this say about the ethics of claiming exclusive reward from Antarctic activities?

Examining the sui generis status of Antarctica will give insight into the differences, if any, between the ethics of bioprospecting and high seas fishing. The purpose of this paper is to explore the ethics of exclusive reward from Antarctic bioprospecting and the fundamental question relates to whether the Antarctic is global commons or its resources, the common heritage of mankind. Connected to this is a query about whether limitations should be put on who has the right to exploit, use and benefit from Antarctic biodiversity above and beyond what exists in law now, and what the broader ethical implications might be.

\section{SUI GENERIS ANTARCTICA}

\section{Where is the Antarctic?}

One of the key factors identified as missing in the bioprospecting debate globally is that of accepted definitions (Netherlands Government 2008; see also CBD 2008). Without knowing exactly the who, what, when, where, why and how of bioprospecting, other matters such as access, jurisdiction or benefit-sharing in the Antarctic context cannot be clarified. In the meantime the onus remains with individual Treaty signatories to provide rules and guidelines for their own scientists undertaking bioprospecting anywhere in the Antarctic. Quite likely, these rules and guidelines will be no different to those applicable to scientific research projects generally there.

Imprecision (or bifocalism as it is sometimes called) is not unusual in the language of Antarctic law and policy. It is the norm rather than the exception. Because there are 28 Consultative Parties, each with an agenda based on their national interests, they have often found it beneficial to keep terms deliberately obfuscatory (for 
example, by leaving them undefined), in order to reach consensus. Even 'the Antarctic' itself is defined in a number of creative ways, depending on who is doing the defining and for what purpose (legal, practical, fisheries management, environmental).

To illustrate this point, one definition of the Antarctic that could be used in the regulation of bioprospecting (and hence would help to clarify other issues such as jurisdiction) is that found within the Antarctic Treaty. The Treaty's area of application is defined as the area 'south of $60^{\circ}$ South latitude, including all ice shelves' (Antarctic Treaty, Art. VI). The status of the seabed will be discussed later. If the ATCPs choose to regulate bioprospecting substantively, their mandate to do so will be derived from the 1959 Antarctic Treaty and it should be a simple matter to adopt its Art. VI area of application in a new regime. However, this kind of simplicity has hardly ever been the case, e.g. the other components in the Treaty System all have different areas of application.

The 1972 Convention for the Conservation of Antarctic Seals (CCAS) has an area of application appropriate to seals: 'the seas south of $60^{\circ}$ South' (Art. 1). However, no account is taken of the terrestrial environment on which seals haul out to molt and breed.

The 1980 Convention on the Conservation of Antarctic Marine Living Resources (CCAMLR) goes some way towards correcting this, with a different area of application based on a biogeographically distinct zone known as the Antarctic Convergence. In some places, this area is further north than the Treaty's $60^{\circ}$ South (CCAMLR, Art. I) and thus includes some sub-Antarctic island territories. Because CCAMLR applies to 'marine living resources' (Art. 1; but not including seals or whales), it is also a potential source of substantive regulation for bioprospecting, particularly if harvesting is involved, as is the case with krill now.

Finally, the 1991 Protocol on Environmental Protection to the Antarctic Treaty (Madrid Protocol), even though it is read in conjunction with its parent Treaty, has its own distinct area described as the 'Antarctic environment and dependent and associated ecosystems' (Madrid Protocol, Art. 2, Art. 3 and elsewhere). The former is the same as in Art. VI of the Treaty; the latter is undefined and may extend the Antarctic boundary north of $60^{\circ} \mathrm{S}$ if the words dependent and associated are taken literally. For example, they could be applied to the foraging range of marine mammals such as Southern elephant seals that migrate between the sub-Antarctic (north of the border) and the continent.

The 4 Antarctic Treaty legal instruments each have different areas of application, which is unhelpful in trying to clarify terms and concepts in bioprospecting. It is essential, therefore, to have a clear understanding of where the Antarctic is located in this context so that if the Parties are contemplating substantive regulation of bioprospecting, as opposed to simply considering the activity of sample collection as scientific research, for example, and regulation is to include limitations on who has the right to exploit, use and benefit from Antarctic biodiversity, relevant and representative boundaries must be drawn up.

\section{Who owns Antarctica and its resources?}

The purpose of this paper is to explore the ethics of claiming exclusive reward for effort in a place where there is no sovereign owner. In 1959 when the Antarctic Treaty was adopted, 7 states (Argentina, Australia, Chile, France, Norway, New Zealand, and the UK) laid claim to parts of the continent (three claims overlapped: those of Argentina, Chile and the UK). Two other states (the USA and the Soviet Union [now the Russian Federation]) reserved their rights to make claims. One section of the Antarctic continent remains unclaimed to this day and is the largest single piece of unclaimed territory on earth. None of these positions have altered since 1 December 1959 when Art. IV of the Antarctic Treaty immobilised the acquisition of territory as a creative means of solving the problem, without actually solving it. Article IV preserves the positions of all Parties (claimant or otherwise) indefinitely to all parts of Antarctica, claimed or unclaimed, and nothing any signatory state does will affect this. If an owner of the Antarctic can be identified, it will help to determine whether, ethically, the international community is due a share of the rewards for effort there.

\section{The Antarctic as global commons}

Given the variety of definitions derived from Antarctic law, and with no sovereign(s) because of Art. IV of the Treaty, is it possible to make a case that the Antarctic is a global commons instead? Global commons are traditionally described as areas beyond national jurisdiction which are terra nullius, owned by no-one and therefore capable of being appropriated, or terra communis, owned by everyone and over which 'no single decision-making unit holds exclusive title' (Wijkman 1982, p. 512-513). Using these descriptions it is possible to make the provisional case that the high seas are global commons and to some extent the continent might also be because it does not actually have one exclusive sovereign. Deciding who owns Antarctica is not as straightforward as this, however. 
Article IV of the Antarctic Treaty preserves the claims to territory as they were in 1959; thus, the claims have not been legally perfected. States parties can (and do) exert their authority but only over their nationals, ships and aircraft while in the Antarctic, as indeed they can anywhere else on the planet (Antarctic Treaty Art. VIII). The position of states parties in relation to high seas rights and duties under other international law is preserved (Antarctic Treaty Art. VI). International law contains numerous constraints on Antarctic Treaty parties, but also opportunities to exercise rights in the Antarctic. For example, the International Convention for the Regulation of Whaling's (ICRW) zero quotas prohibit commercial whaling for any species anywhere, while its Art. VIII allows the taking of whales in the Southern Ocean through a scientific research permit provision. Similarly, the UN Convention on the Law of the Sea (LOSC) Art. 87 permits freedom of navigation through Antarctic waters. It also permits freedom to fish, but this is constrained through the duty to cooperate with fisheries management agencies in Art. 117 (LOSC). In addition, the Antarctic - as defined in CCAMLR - contains undisputed sovereign territory wherein States parties can exercise jurisdiction exclusive of other states and in some respects, exclusive of CCAMLR conservation measures as well, as established in the Chairman's Statement appended to the Final Act of the conference adopting CCAMLR.

Furthermore, it could be argued that south of $60^{\circ}$ South is no longer strictly beyond national jurisdiction since the Commission on the Limits of the Continental Shelf ratified the coordinates of Australia's extended continental shelf off Heard Island and the McDonald Islands, and Macquarie Island, both of which extend south into the Antarctic Treaty area (Jabour 2008a). The Australian government has thus been granted the right to extend its exclusive jurisdiction over the area of the seabed and subsoil within this extended continental shelf zone (Jabour 2008a). However, Australia also has a corresponding duty to share benefits from minerals extraction from the seabed of the extended zone, as set out in LOSC Art. 82, from the 200 nmile exclusive economic zone boundary seawards. This is because the LOSC legally invokes the common heritage of mankind designation for the deep sea bed beyond national jurisdiction.

Antarctic resources as common heritage of mankind

The concept originated during the third UN Law of the Sea conference in 1967, when Ambassador Pardo from Malta successfully appealed for the deep sea bed, beyond areas of national jurisdiction, to be considered the common heritage of mankind (UN Doc. A/6695, 1967). In this context, Ambassador Pardo is interpreted to have meant that the deep sea bed should not be owned by anyone; management and benefits should be shared; it should be used exclusively for peaceful purposes; and the deep sea bed should be conserved for mankind, including future generations (Joyner 1986, Larschan \& Brennan 1982, Weiss 1989, Keyuan 1991).

Like other buzzwords and phrases, 'common heritage of mankind' tends to be used indiscriminately and inappropriately. However, interpretive guidance can be had from the international law instruments that formally encode it, e.g. LOSC where common heritage applies to the deep sea bed beyond national jurisdiction (LOSC Preamble). LOSC came into force on 16 November 1994, thus giving legal effect to common heritage of mankind.

In addition to the deep sea bed, outer space, the moon and other celestial bodies are also locations where the common heritage designation has the force of law. In the Outer Space Treaty, for example, the following guiding principles were outlined as the first 3 articles:

(1) The exploration and use of outer space shall be carried on for the benefit and in the interests of all mankind.

(2) Outer space and celestial bodies are free for exploration and use by all States on a basis of equality and in accordance with international law.

(3) Outer space and celestial bodies are not subject to national appropriation by claim of sovereignty, by means of use or occupation, or by any other means.

Furthermore, the Convention on Biological Diversity (CBD) expresses a common heritage-like concept with regard to global biodiversity (e.g. 'common concern of humankind', CBD Preamble). It is argued that global climate is also a global concern; however, common heritage of mankind, per se, does not have an unambiguous legal definition and may not stand independently of those treaties that invoke it (Triggs 1986). Persistent usage and common interpretation may alter this perception in time but there are few, if any, actual instances of the concept becoming a reality, almost as if it had no legal substance. Recent work by the International Seabed Authority (ISA), for example, concluded that the common heritage privileges available through LOSC Art. 82 ('Payments and contributions with respect to the exploitation of the continental shelf beyond 200 nautical miles') are 'dormant' because of difficulties of implementation (ISA 2009).

Common heritage and global commons may be noble ideals but they do not find support among the ATCPs, most of which are highly developed western 
countries that do not, themselves, stand to benefit from access or benefit-sharing arrangements from any current bioprospecting activities.

\section{The commons concepts and Antarctic governance}

Of note is the fact that none of the international conventions mentioned above that expressly allocate benefits to the international community has, as yet, paid out (e.g. invoking LOSC Art. 82 or Art. 140, 'Benefit of mankind' for deep sea bed mining). This is primarily a consequence of there being no current minerals exploitation on the seabed and no attempts by a sovereign state to annex Outer Space or the Moon.

Furthermore, no express legal provisions have appeared in current Antarctic instruments either, nor are they likely to be forthcoming (Jabour \& Weber 2008). The Antarctic Treaty, while expressly acknowledging 'all mankind' (Preamble) and the benefits of peace and science, does not provide a mechanism in it, or in any of its active subsequent legal instruments, for sharing the benefits of Antarctic resources. This is linked to the need to make decisions by consensus. It is unlikely that a positive political outcome would be had from states Parties going it alone on bioprospecting in the Antarctic.

Assuming, arguendo, that the sub-text of global commons and common heritage is about access and benefit-sharing, the ATCP position can be exemplified by their response to the actions of the G77 in the United Nations during the 1980s (Beck 1986, Tepper \& Haward 2005). During this time, Malaysia - speaking on behalf of the group - noted, among other things, that the ATCPs were negotiating a minerals convention but that the Antarctic should be considered the common heritage of mankind with all states, particularly developing states, able to gain access and share the benefits from any regime to exploit minerals. Their arguments rested on Malaysia's perception that Antarctic resources were common property, unable to be appropriated by any single state. Counter arguments from the Treaty Parties were minimalist: Ignoring questions about benefit-sharing from Antarctic resources, it was simply pointed out that accession to the Antarctic Treaty was open to any state Member of the United Nations (e.g. UN Doc A/C.1/38/PV.42 [1983]), as if this was the only barrier between developing countries and Antarctic resources.

When the minerals regime dissolved in 1989 in favour of an environmental protocol to the Treaty that prohibited mining, G77 interest in Antarctica began to dissolve as well. Only Malaysia has remained involved. Each year since 2002 it has been invited to observe at the ATCM and each year it is encouraged to accede to the Antarctic Treaty. Malaysia considers but rejects this encouragement, preferring instead to continue accepting invitations to attend ATCMs, which the ATCPs continue to issue, and securing places for its scientists with ATCP scientific programs heading south (e.g. with the Australian Antarctic Program). It is understood that Malaysia's reluctance to accede to the Antarctic Treaty is based partially on the fact that its objection to Art. IV regarding claims cannot be upheld by a reservation to this article because reservations are not permitted under the Treaty. However, Art. IV would in fact support Malaysia's basis of objection to some degree because it allows both claims and nonrecognition of claims to co-exist

Ironically, the concepts of access and benefit-sharing were formally adopted in the 1988 Convention on the Regulation of Antarctic Mineral Resource Activities (CRAMRA), to which the G77 was so strongly opposed. CRAMRA contained provisions acknowledging that participation should be open to all states, particularly developing ones (Preamble Para. 12) and that the interests of the international community as a whole should be taken into account in decisions about mineral resource activities (Art. 2.3[g]). Within CRAMRA there were also provisions for the exchange of money earned from fees payable for various activities, but there were no instructions for disbursement of money in excess of budgetary requirements to developing countries or any other party. This function was to be the responsibility of a Commission, established under Art. 21. CRAMRA never entered into force, however, and formal access and benefit-sharing arrangements have not reappeared.

Today the Antarctic Treaty System (ATS) regulates all uses of the Antarctic, meaning that the region is no longer as vulnerable to Hardin's overuse 'tragedy' scenario as it once was, during such times as the pursuit of the great whales, for example, or potentially through minerals exploitation. The international community is rewarded for its faith in the ATS by receiving a relatively healthy Antarctic environment and having free access to some scientific information such as climate change forecasting and the status of biodiversity. Whether this is what the international community would prefer is a moot point.

\section{THE ANTARCTIC APPROACH TO BIOLOGICAL DIVERSITY}

Putting aside the questions of whether the Antarctic is or is not global commons or its resources (including its environment) the common heritage of mankind, limitations already exist on who can access resources and benefit from its biological diversity or its clean environment (noting also that all Treaty Parties are 
prohibited from non-living resources extraction, though not scientific research, under the provisions of Article 7 of the Madrid Protocol).

\section{Access to biological resources}

The ATS has a range of legal instruments regulating access to biological resources. Essentially, all living things are given broad-ranging protection under the Madrid Protocol (especially Annex II-the Conservation of Antarctic Fauna and Flora), with an emphasis on access for purposes of scientific research. Even specially protected species can be taken (within the specific meanings attributed to that term under Art. 1, Annex II) in accordance with a permit, for essential science. Some species also have more specific protection.

Seals, for example, are not covered under CCAMLR; rather, they can be harvested in accordance with the regulatory regime established by CCAS, but only by the nationals of signatory states. CCAMLR Commission Members can harvest other marine living resources such as fin-fish and squid in accordance with the Convention and in compliance with conservation measures designed according to ecosystem-based management principles. Whales are also not covered under CCAMLR. The ICRW protects whales broadly under its Southern Ocean Whale Sanctuary and specifically from commercial harvest under its zero quota arrangements. However access can be gained through other scientific provisions of the ICRW. Under Art. VIII, signatories can assign their nationals rights to take whales for research, even by lethal means, and through the Reservation provisions in the ICRW, which Japan uses to object to sanctuary being given to Minke whales in the Southern Ocean.

It is not surprising then, that there is no consistency of approach to Antarctic biological resources. Some species are considered purely utilitarian (e.g. Patagonian toothfish); others are both iconic and utilitarian (e.g. krill and whales). Krill - the keystone zooplankton species in the Antarctic food web-is also harvested and increasingly being used in bioprospecting industries, despite there being no accurate estimate of its biomass (Belgium et al. 2009, SC-CAMLR 2009). Whales, on the other hand, are so iconic to some that all species are specially protected-irrespective of their conservation status - while to others whales are simply seafood. Species such as phytoplankton attract relatively low interest in terms of bioprospecting but have a central place in the Antarctic ecosystem (e.g. krill eat phytoplankton). Fur seals, the stocks of which were decimated in the 1800 s, recently had their Specially Protected Species status under the Madrid Protocol revoked because of a dramatic recovery in some population numbers, but without future management plans in place (Jabour 2008b). Finally, while the ATCPs have consistently acknowledged obligations to protect Antarctic species from the introduction of alien species that could decimate naïve native populations, even more so in a warming climate, they have hitherto been unable to agree on basic first steps such as common quarantine protocols between the gateway ports. The lack of a consistent approach to Antarctic biological resources makes the debate about the ethics of biological prospecting even more multifarious.

\section{Benefit-sharing arrangements}

There are a number of phases of bioprospecting, given different titles by different authors but essentially relating to the activities of sample collection, isolation, screening for bioactivity, and product development. The first phase of sample collection may be quite straightforward, with no major environmental implications and no further regulation required other than what is already provided for in the ATS (especially the environmental Madrid Protocol). Sample collection is most likely to come under the rubric of science and be given only cursory legal attention as all ATS instruments give priority to scientific research.

The subsequent phases are usually carried out ex situ in laboratories around the world; however, in some cases it might be necessary to undertake in situ resampling. Without adequate knowledge about who is bioprospecting, what they are taking, when, where, why and how, it is difficult to clarify the legal position regarding to access to or possible future ownership of these resources. Without this kind of certainty, prospectors may be turned away or driven underground, providing even less chance of facilitating benefit-sharing arrangements (CBD 2008). Complicating factors include the lack of specific regulation of Antarctic bioprospecting, industry protection of intellectual property rights if bioactivity potential is identified, and the duty to disclose the origin of biological resources, as required under the proposed Art. $29 \mathrm{bis}$ of the Agreement on Trade-Related Aspects of Intellectual Property Rights - TRIPS (Straus 2008).

The problems in Antarctica are mirrored elsewhere in the world, even though similar barriers do not exist. While states have agreed in principle about access, benefit-sharing and maintaining the integrity of the patent system, they have not been able to agree on how to achieve these objectives (Straus 2008). Furthermore, even those states that do have national legislation embodying these 3 objectives (which are easier to achieve under circumstances where ownership of resources is known) have not met basic CBD require- 
ments for clear, simple and transparent arrangements or balanced competing interests (Straus 2008). With these difficulties in mind, it is not evident how the ethical or moral issues of access and benefit-sharing for the common good of all mankind can be approached in the Antarctic context.

\section{BASIC ETHICS}

Our 21st century Western society has inherited ethics discourse from Pythagoras, Plato and Aristotle, among many others. To paraphrase the ancient philosophers who studied and wrote about society, harmony was a condition to be desired because it produced order, and vice versa. Harmony and order equated to ethical behaviour, supported by the rules that both guided and constrained our everyday lives. Without these rules we would have anarchy and injustice. This understanding might evoke a sense of the common good and reciprocity - mutual rights and obligations - in many people because common good and reciprocity are the cornerstones of acceptable behaviour in today's society. But equally, it may not. Theories about how to make ethical choices (i.e. how to do the right thing), while noble, are pragmatically naïve because of their complexity. For example, compare the differences between these attributes:

$$
\begin{gathered}
\text { Consequences vs.behaviour } \\
\text { Behaviour vs. consequences } \\
\text { Common good vs. self-interest } \\
\text { Good }=\text { happiness, therefore good }=\text { ethical behaviour } \\
\text { Motive }=\text { good }=\text { ethical behaviour }
\end{gathered}
$$

Kant, a German philosopher, determined that ethics was based on reasoning about all of these different attributes. He thought the best test of whether a decision was good (and therefore ethical) was whether it could be applied to everyone. Kantians argue that if the motive is correct the behaviour is ethical, irrespective of the consequences (Oz 1994, Kallman \& Grillo 1996, Landeweerd et al. 2005). If the ATCPs were trying to make decisions about bioprospecting in Antarctica, particularly about granting access to resources and a share of the benefits to third parties from the efforts of others, there is no elegant answer to how things should be, or how to balance motives and goodness or the common good and self-interest.

To illustrate this point, would a multinational drug company pay compensation for sourcing material from Antarctica? Who will ask the company, which would have spent maybe 10 to $15 \mathrm{yr}$ and many millions of dollars in research and development, to share its profit with the rest of the world? When will it be asked to pay up: at the sample-collection phase; when bioactivity is first indicated; when the product is developed; or when the product is sold? Who distributes this windfall to all mankind? Should the windfall be applied more usefully to a fund supporting ongoing Antarctic research and thus indirectly benefit mankind?

Making decisions that have these kinds of ethical complexity attached to them will involve the ATCPs making value judgments. These will be based on the values of individual states (and influential individuals within bureaucracies), adequate examination of the facts, consideration of all perspectives, consequences of alternatives, and ultimately what is most beneficial to the state. Traditional ethical philosophies about common good and ethics become more tenuous when recipients of personal and/or commercial rewards (e.g. scientific reverence, profits from end product sales or licensing) are obliged to share those rewards with others who have made no contribution to the process. This forced munificence on the part of the giver takes the stakes well beyond a simple appeal to altruism; money is involved, and the objective of bioprospecting is, first and foremost, a commercial one. Notwithstanding, altruistic obligations have been translated into legal norms and given expression in modern international environmental law, most notably in relation to the deep sea bed (Brunnée 2007) as described above. Precedent does exist, even though actual benefits have not yet begun to flow. Does this make the current thinking of the ATCPs with regard to the taking of exclusive reward from commercial Antarctic activities like bioprospecting unethical?

\section{DISCUSSION}

A recent high level think-tank on future challenges and possibilities for the polar regions in a changing climate, reported that a 'business as usual' approach to polar governance may not be sustainable in the long term and that it was vital that the ATCM regained its previous proactivity by dealing with issues before they became reality or contentious, enabling negotiations to proceed in the absence of vested interests (Polar Regions Unit 2007, p. 7). The think-tank regarded the issue of bioprospecting as 'important' and noted that it was under the consideration of the UN; furthermore, they pinpointed both governance and economics as issues specifically for the attention of the ATCPs in the future (Polar Regions Unit 2007, p. 3). Bioprospecting has all the hallmarks of a troublesome issue for the ATCPs: it already exists, there are vested interests and there is no specific regulation.

To show the scale of the problem, it is informative to look at just one aspect of bioprospecting: the filing of patents. Using information on patents registered in the 
European and US Patent Offices since the 1970s, Foster et al. (2009) constructed a database to detect trends in the krill fishery of the Southern Ocean. The research, originally published in 2003 and updated in 2009 , aimed to test whether the increase in notifications required by CCAMLR for new and exploratory fisheries for krill matched patent registrations. In an attempt to understand the discrepancies between notifications of intent to harvest krill and actual reported catches, the CCAMLR Scientific Committee had previously asked Members to supply krill market information (prices, economics of the fishery, products; Nicol \& Foster 2003) and in 2008 again asked Members for information specifically on product types to be derived from krill catches (Foster et al. 2009).

Of all the potential bioprospecting activity in the Southern Ocean, it was thought that the harvesting of marine species such as krill was the least-problematic scenario because of the existence of the CCAMLR regulations and their remit to conserve and use rationally 'the populations of fin-fish, molluscs, crustaceans and all other species of living organisms, including birds' (CCAMLR Art. 1; Jabour-Green \& Nicol 2003). Krill harvesting has been carried out in the Southern Ocean since the 1970s, for a variety of uses (Nicol \& Foster 2003). The patent database (Foster et al. 2009) shows continuing global interest in the development of patents for krill products (Fig. 1), and how expectations about the potential uses of krill have changed from krill for human food to krill for human use, particularly medicines (Fig. 2).

The Foster et al. (2009) database confirms existing knowledge that krill are being harvested for human use (pharmaceutical applications) and as an aquaculture food stock rather than for human consumptiontheir original use. Japan and Poland are 2 fishing states that originally dominated the patent activity, but lately they have been overshadowed by the progressive increase in patents being lodged by US and Canadian entities. This leads to the conclusion that it is too late for the ATCPs to consider bioprospecting as a hypothetical activity. The patent database established by Foster et al. (2009), and the Bioprospector database discussed earlier, clearly show that activity has gone far beyond this point. Accordingly, it is also too late to develop a commons conscience. While it is certainly not too late to invent a new system to manage bioprospecting, it is highly unlikely in the near future given the current frame of mind of the ATCPs who, in 2009, decided that: '...the Antarctic Treaty system is the appropriate framework for managing the collection of biological material' although they agreed to continue to raise the matter at their meetings (ATCPs 2009, Resolution 9).

On the face of it, the taking of biological specimens from the Southern Ocean or the Antarctic continent in the quest for potential novelty and bioactivity should not be seen as activitites that have an ethical or moral

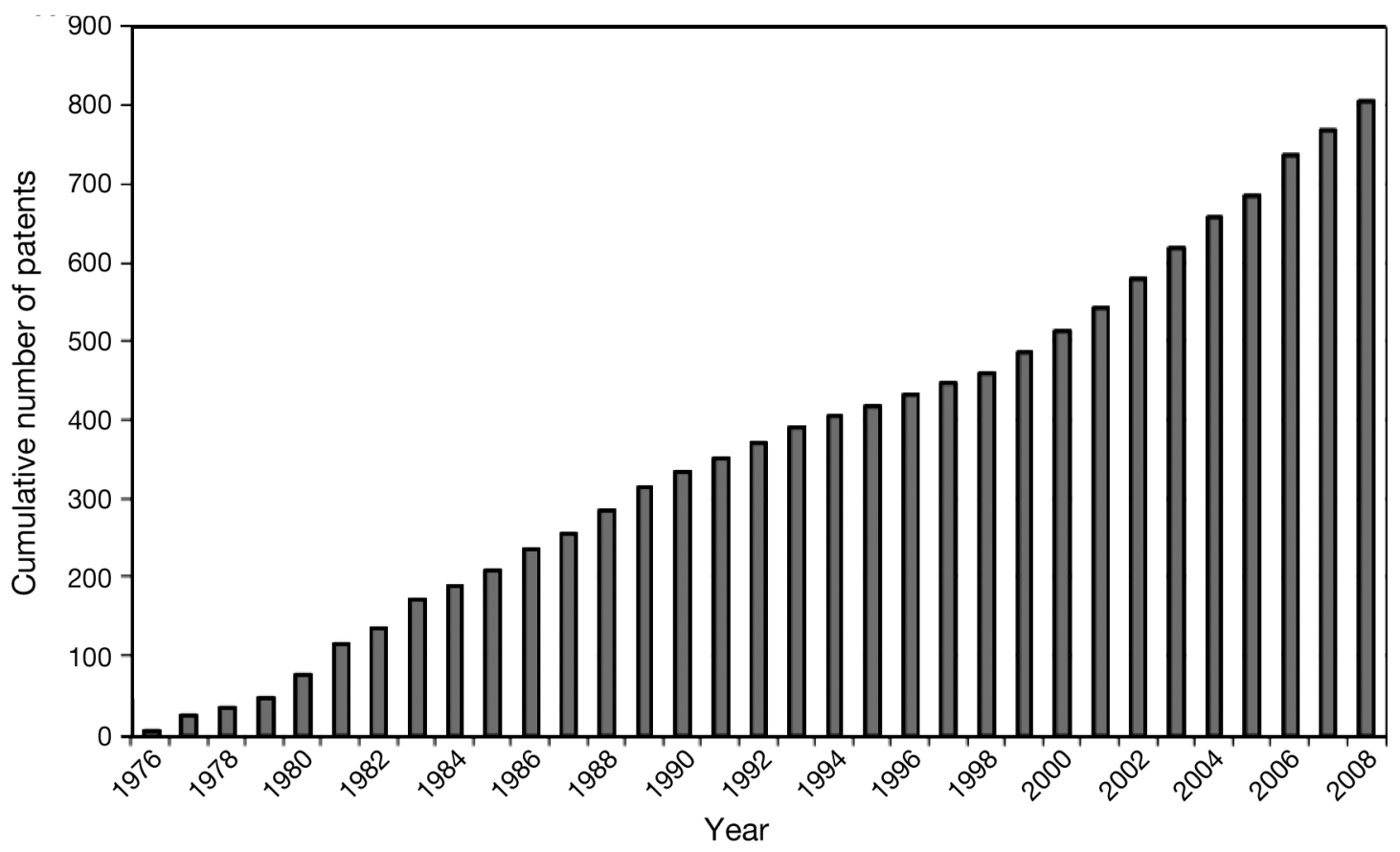

Fig. 1. Cumulative number of krill-related patents lodged from 1976-2008. (Source, and to be viewed in conjunction with, Fig. 2 in Foster et al. 2009. Used with permission) 


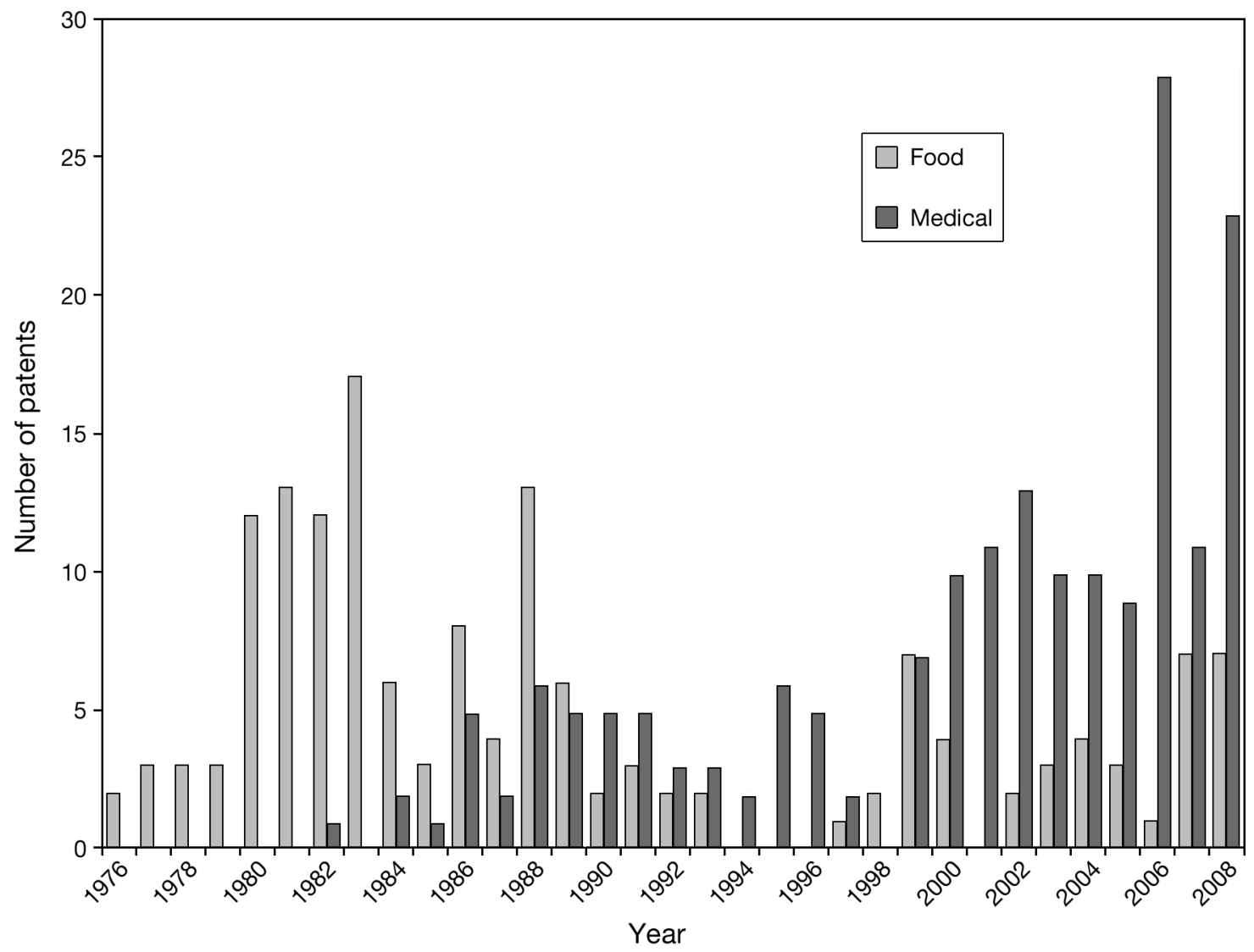

Fig. 2. Comparison of krill-related patents for food and medicinal use. Note that krill for aquaculture food stock surged in the hiatus period of the 1990s. (Source, and to be viewed in conjunction with, Fig. 6 in Foster et al. 2009. Used with permission)

contradiction to them. Rather, bioprospecting is a commercial venture balanced on a substrate of legitimate scientific research, not unlike Southern Ocean high seas fishing. In the case of bioprospecting, as with fishing, ownership of the resources (e.g. krill) will be conferred on the proponent (the bioprospector or the fisher) by the laws of his sovereign state (which may have been guided by relevant Antarctic regulation) but with no consideration whatsoever for the whole of mankind as a beneficiary.

Even if it could be argued that the Southern Ocean is a global commons where resources belong to everyone, exclusive rewards are being derived from those resources. Southern Ocean fishers harvest fish for their own benefit, even though yield is based on an allowable catch for the whole fishery calculated through scientific research and regulated through legal and administrative frameworks. Fishers do not fish for purely egalitarian reasons, i.e to feed masses of starving people, even though the World Health Organization lists malnutrition, especially in developing countries, as a major health problem that moral imperatives dictate every capable human should help to address (WHO 2009). High seas fishers are rewarded for their effort by selling their fish in the marketplace. The market makes the product of the fishers' labours accessible to anyone who has purchasing power, having first established a margin of profit for itself. Reward is not guaranteed, however. The fishers might not catch enough fish to make their voyage economically viable; the market might be saturated with fish, bringing the price down; they might strike bad weather or lose gear or have a fire onboard that would render them in grave danger; or flag states might impose excessively large license fees to try to reduce overcapacity in the fishing fleet. Both the burden and the risks lie squarely with the fishers, so why should Antarctic bioprospecting be treated differently to fishing?

In the case of bioprospecting, the investor is the risktaker. Access to resources in an unusual, unowned place like the Antarctic may not be guaranteed, as the investor is not able to deal directly with one sovereign government to negotiate current industry standard conditions such as prior informed consent or the means of fair and equitable sharing. Even at sovereign state level these conditions are problematic and developing countries argue that more needs to be done to secure their so-called rights in relation to bioprospecting 
(Straus 2008). In the Antarctic, however, the investor may need to do little more than source original material from the region, perhaps accomplished through a small scientific project, and may never need to resample or even harvest.

As mentioned, one drawback in trying to apply commons concepts to Antarctic bioprospecting is actually a structural one: there is no institution to undertake the functions of a surrogate sovereign. The ATCPs have carte blanche to discuss matters of relevance to the Antarctic, make decisions by consensus at each annual ATCM and take recommendations to their governments for action. Yet the ATCM itself ceases to exist, per se, at the end of each meeting, only to be resurrected again the following year. In the interim, the Antarctic Treaty Secretariat - the administrative servant of the ATCM - has no autonomy and no power beyond what is necessary to carry out its functions. Considering the disparate groups of signatories (claimants, non-claimants and others) and the long and complex history leading to the adoption of the Secretariat, granting the organisation institutional autonomy outside the ATCM would be unlikely (or even unthinkable).

\section{CONCLUSION}

Bioprospecting is an activity that lives up to all the very high egalitarian expectations laid out in the 1959 Antarctic Treaty, including those of peace and the free exchange of scientific information (Guyomard 2006). Moreover, exclusive reward from bioprospecting is as legitimate as exclusive reward from fishing for the signatories to the relevant instruments of the ATS. The Southern Ocean under CCAMLR is not a global commons in relation to all Antarctic marine living resources (CCAMLR Art. 1) as access is both controlled and competency-based. The marine species most likely to be bioactive are also ostensibly covered under CCAMLR's rules about harvesting and conservation (although this is yet to be fully tested). If non-living or sedentary resources from the deep sea bed become the object of bioprospecting activity, they will be freely accessible while the only activity involves sample collection-euphemistically called marine scientific research promoted specifically by the ATS and protected generally by the LOSC. If living terrestrial resources are bioprospecting targets (e.g. microbes in soil), nationals of signatory states to the Antarctic Treaty/Madrid Protocol can freely access them, in accordance with obligations including to conduct environmental evaluation and respect special provisions that may apply (e.g. permits to enter specially protected areas). If non-living terrestrial resources are of interest, then provided that the activity of sample collection constitutes scientific research rather than mineral resource activities prohibited under Protocol Art. 7, access is also freely available to signatory states. If sample collection is all that actually occurs in the Antarctic, then reporting the findings, even as simply as describing taxa in the academic literature, will suffice in terms of obligations owed to all mankind under the provisions requiring the '[sharing of] scientific results and observations from Antarctica' (Treaty Preamble and Art. III).

Notwithstanding, the ATCPs can choose to make new regulations about bioprospecting that do incorporate equitable access or at least benefit-sharing schemes. This could not cover the activities of third party states because their consent would be required, and in any case the ATCPs would be confident that while representing less than $25 \%$ of the world's states the 47 Treaty signatories realistically embody the sum total of global interest in and capacity to undertake Antarctic bioprospecting, ironically with the possible exception of Malaysia (Tepper \& Haward 2005). Furthermore, it is highly unlikely that the ATCPs would hand over regulation of Antarctic bioprospecting to a third party such as the United Nations. They have resisted all attempts in the past to have the UN involved in Antarctic affairs in any way other than by invitation.

It might be possible for the ATCPs to reach consensus on such schemes as the payment of fees by commercial bioprospectors into a common fund to support Antarctic science, royalty payments into the same fund for commercially successful products, and an open-access sample receptacle for common usage (Jabour-Green \& Nicol 2003). Each one is a means of sharing benefits that does not involve the direct transfer of money from industry to developing countries and in each case does not leave the Antarctic environment open to a resources rush with potentially negative consequences.

The prospect of a challenge by developing countries based on commons arguments is remote, to say the least, and the supremacy of the ATCPs goes unchallenged today, $50 \mathrm{yr}$ into their governance. It is plain from their behaviour that they do not embrace commons arguments except insofar as the individual legal instruments promote peace, cooperation and science, and environmental safeguards to help retain environmental integrity. Developing countries are naturally limited in their ability to access Antarctic resources, due in part to a lack of capacity, and the argument the ATCPs would run - if challenged on how Antarctic activities benefit all mankind - is to offer peace, scientific results and a pristine environment as alternatives, thereby satisfying any possible contradiction over ethics. 


\section{LITERATURE CITED}

ATCP (Antarctic Treaty Consultative Parties) (2009) Resolution 9 (2009) ATCM XXXII-CEP XII, Baltimore, MD

Beck P (1986) Antarctica at the United Nations, 1985: the end of consensus? Polar Rec 23:159-166

Belgium, Brazil, Bulgaria, Finland, France, Germany Netherlands, Sweden (Governments of) (2009) The Antarctic Biological Prospecting Database. WP1 to ATCM XXXII:6

Brunnée J (2007) Common areas, common heritage, and common concern. In: Bodansky D, Brunnée J, Hey E (eds) The Oxford handbook of international environmental law. Oxford University Press, Oxford, p 550-573

CBD (Secretariat of the Convention on Biological Diversity) (2008) Access and benefit-sharing in practice: Trends in partnerships across sectors. Tech Ser No. 38

Foster J, Nicol S, Kawguchi S (2009) The use of patent databases to detect trends in the krill fishery. Paper submitted by the Government of Australia to SC-CAMLR-XXVIII, Agenda Item 4 (i) a

Guyomard AE (2006) Bioprospecting in Antarctica: A new challenge for the Antarctic Treaty System. In: Francioni F, Scovazzi $T$ (eds) Biotechnology and international law. Hart, Oxford, p 147-169

ISA (International Seabed Authority) (2009) Issues associated with the implementation of Article 82 of the United Nations Convention on the Law of the Sea. ISA Tech Stud No. 4

Jabour J (2008a) The Australian continental shelf: Has Australia's high latitude diplomacy paid off? Mar Policy 33: $429-431$

Jabour J (2008b) Successful conservation-then what? The de-listing of Arctocephalus fur seal species in Antarctica. J Int Wildl Law Policy 11:1-29

Jabour J, Weber M (2008) Is it time to cut the Gordian knot of polar sovereignty? Rev Eur Comm Int Environ Law 17(1): $27-40$

Jabour-Green J, Nicol D (2003) Bioprospecting in areas outside national jurisdiction: Antarctica and the Southern Ocean. Melbourne J Int Law 4(1):76-111

$>$ Joyner CC (1986) Legal implications of the concept of the common heritage of mankind. Int Comp Law Q 35: 190-199

Kallman EA, Grillo JP (1996) Ethical decision making and

Editorial responsibility: David Walton,

Cambridge, UK information technology: an introduction with cases. McGraw-Hill, New York

Keyuan Z (1991) The common heritage of mankind and the Antarctic Treaty System. Neth Int Law Rev 38:173-198

Landeweerd L, Houdebine LM, Termeulen R (eds) (2005) BioTechnology ethics: an introduction. IAAS-EDAP (International Association for Arts and Sciences), Angelo Pontecorboli Editore, Florence

Larschan B, Brennan BC (1982) The common heritage of mankind principle in international law. Colum J Transnatl Law 21(2):305-337

Netherlands Government (2008) Report of the ATCM Intersessional Contact Group to examine the issue of biological prospecting in the Antarctic Treaty Area. WP4, ATCM XXXI

Nicol S, Foster J (2003) Perspective-Recent trends in the fishery for Antarctic krill. Aquat Living Resour 16:42-45

Oz E (1994) Ethics for the information age. Business and Educational Technologies, Dubuque, IA

Polar Regions Unit (2007) Polar regions: Challenges and possibilities. Report of the Chair of the Meeting held at Wilton Park, UK, 1-4 October, 2007. Polar Regions Unit, UK Foreign and Commonwealth Office, London, p 3

SC-CAMLR (2009) Report of the Twenty-eighth Scientific Committee of CCAMLR. CCAMLR, Hobart, Tasmania

Straus J (2008) How to break the deadlock preventing a fair and rational use of biodiversity. J World Intellect Prop 11: 229-295

Tepper R, Haward M (2005) The development of Malaysia's position on Antarctica: 1982 to 2004. Polar Rec 41:113-124

Triggs G (1986) International law and Australian sovereignty in Antarctica. Legal Books, Sydney

UNU-IAS (United Nations University-Institute of Advanced Science) (2009) Antarctic Bioprospector database. UNUIAS, New York, www.bioprospector.org/bioprospector/ antarctica/home.action

Weiss EB (1989) In fairness to future generations: International law, common patrimony and intergenerational equity. United Nations University, Transnational Publishers, New York

WHO (World Health Organization) (2009) Nutrition. www. who.int/nutrition/en (accessed Nov 5, 2009)

- Wijkman PM (1982) Managing the global commons. Int Organ 36:511-536

Submitted: November 27, 2009; Accepted: March 1, 2010

Proofs received from author(s): April 20, 2010 